\title{
Determination of Liberation Degree of Mechanically Processed Waste Printed Circuit Boards by Using the Digital Microscope and SEM-EDS Analysis
}

\author{
Pedro Pereira Gonçalves ${ }^{1}$ and Akira Otsuki ${ }^{1,2, *}$ \\ 1 Ecole Nationale Supérieure de Géologie, GeoRessources UMR 7359 CNRS, University of Lorraine, \\ 2 Rue du Doyen Marcel Roubault, BP 10162, 54505 Vandoeuvre-lès-Nancy, France; pedro.pcpg@gmail.com \\ 2 Waste Science \& Technology, Luleå University of Technology, 97187 Luleå, Sweden \\ * Correspondence: akira.otsuki@univ-lorraine.fr; Tel.: +33-3-72-74-45-43
}

Received: 26 July 2019; Accepted: 15 October 2019; Published: 22 October 2019

check for updates

\begin{abstract}
Characterization of heterogeneous materials, such as particles from mechanically processed waste printed circuit boards, is a challenging task. The majority of characterization methods either give average information or information that is very limited and in a tiny area of specific interest. That said, capturing such heterogeneity is significantly important for any kind of processes. Degree of liberation, indicating how much the target component is liberated from the non-valuable components, is a key property to determine the success of subsequent process for valuable material recovery. This work analyzed the degree of liberation of metals within the products of hammer milling process via the combination of image acquisition and analysis. The digital microscope and a scanning electron microscope (SEM) coupled with the energy dispersive spectroscopy (EDS) were used for image acquisition and elemental mapping, in order to evaluate the selective liberation under different milling conditions (i.e., feed mass, milling time) for different metals (mainly $\mathrm{Cu}$ and $\mathrm{Al}$ ) and particle size fractions. The obtained liberation degree was also modelled and determined the liberation parameters that were compared. The results showed that the degree of liberation significantly depend on the milling conditions and metals we analyzed, and well correlated with the selective metal enrichment behavior. Results between the two methods showed some similarities and discrepancies. The advantages and disadvantages of the above two methods were identified and discussed in the paper, in addition to their methodological developments.
\end{abstract}

Keywords: complex material; heterogeneity; metal recovery; recycling; circular economy; scanning electron microscope

\section{Introduction}

Waste electrical and electronic equipment (WEEE) is one of the fastest growing waste categories in the EU, with the growth rate of 3-5\% per year [1], as a result of massive production of the EEE and its market expansion based on technological progress. The printed circuit boards (PCBs) present in almost every single piece of electronic equipment, and account for roughly $5 \mathrm{wt} \%$ of the entire e-waste currently produced. Nevertheless, they carry the most important share of the valuable and also toxic metals $[2,3]$. This creates an urgent need for recovering/recycling valuable materials from PCBs. On the other hand, their complex and heterogeneous structures (e.g., mixture of number of different metals, plastics, and ceramics in different sizes) and their diversion with time raise the issues associated with their effective pre-concentration process development as well as environmental concerns. One of the major limitations in the recycling of PCBs is a lack of a proper characterization method to quantitatively evaluate the distribution and liberation of each metal without destroying the heterogeneous particle status at each separation/beneficiation unit operation. 
The degree of liberation, indicating how much the target component is liberated from the non-valuable components, is a key factor when establishing the liberation performance of the comminution to determine the success of subsequent process for valuable material recovery [4]. The study of the degree of liberation was initially introduced in the mineral processing field, where the main objective was to achieve selective liberation of the valuable minerals of interest aiming for the coarsest particle size possible, saving energy on the grinding process and reducing the amount of non-desirable fine fractions produced $[5,6]$.

One of the methods for the degree of liberation for mineral grains is the analysis of images (and elemental maps) obtained by optical microscopy or scanning electron microscopy. For instance, there was a report on liberation within complex assemblages, such as in a Galena-Sphalerite ore [7]. In the mineral industry, the image analysis has shifted towards an automatic procedure lately, using automated analyzers coupled with the electron microscopes, such as MLA and QEMSCAN [8,9]. However, the applicability of the automated image analyzers algorithms to electronic wastes, mostly for such complex assemblage resulting from the waste PCBs can be challenging [10]. The heterogeneous nature of the samples, in terms of diverse materials used (i.e., metals, glass, ceramics), the irregular shape of the particles due to the different physical properties of the materials (e.g., round ball-like shaped, elongated rod-like shapes, cubic-like [11]) and associated software developed for mineral analysis are some of the issues that could face by automated analysis. Hence, particle counting method is preferred for the conditions and heterogeneous samples of our study in order to evaluate and understand the liberation degree of the metals of interest, by applying a non-destructive characterization. The importance of using non-destructive characterization methods and how it can be helpful to understand the association and deportment of metals/plastics in the different size fractions was alerted in our previous studies e.g., [12].

Comparing with the primary ore beneficiations, in a waste PCB assemblage, a specific size fraction for the liberation of valuable metals from non-metallic fractions is still not clearly understood. Some previous studies investigated the effect of the particles size and shape on the liberation characteristics [11,13], and high liberation degree was reported with the particle sizes below $<100 \mu \mathrm{m}$ or from $100 \mu \mathrm{m}$ up to $3 \mathrm{~mm}$. Such discrepancies are likely related to the differences in the PCB material compositions and the grinding mechanisms used in the comminution processes [14].

Our previous work [15] reported the selective metal enrichment and agglomeration of metallic components (e.g., $\mathrm{Cu}, \mathrm{Al}$ ) through the application of a hammer milling for PCBs comminution. Based on our results and abovementioned research gaps, the objective of the present study is to assess the degree of liberation of metals within the products of hammer milling process via the combination of image acquisition and analysis, in order to evaluate their selective liberation. The particles produced under different milling conditions (i.e., feed mass, milling time) for different metals (i.e., $\mathrm{Cu}, \mathrm{Al}$ ) were compared as a function of particle size fractions. The results obtained for the liberation degree using digital optical microscopic images were compared with the analysis of backscattered electron (BSE) images and elemental maps obtained by scanning electron microscope coupled with an energy dispersive spectroscopy (SEM-EDS). The advantages and disadvantages of the above two methods for investigating the liberation degree of mechanically processed PCB particles will be discussed in the paper, in addition to their methodological developments.

\section{Materials and Methods}

\subsection{Materials}

Printed circuit boards (origin confidential) were comminuted through shredding and hammer milling, without prior detachment of components. An experimental matrix was designed to investigate the influence of two of the hammer milling parameters, feed mass (20,40 and $80 \mathrm{~g})$ and grinding time (30, 60 and $90 \mathrm{~s})$ on the selective enrichment of metals from the non-metallic fractions in the milled products. The detailed milling procedure was presented in our previous report [15]. The hammer 
milled PCB products were then sieved to obtain the following size fractions: $1-2 \mathrm{~mm}, 0.5-1 \mathrm{~mm}$, $0.25-0.5 \mathrm{~mm}, 0.125-0.25 \mathrm{~mm}$, and $<0.125 \mathrm{~mm}$.

\subsubsection{Scanning Electron Microscope (SEM) with Energy Dispersive Spectroscopy (EDS)-Sample Preparation}

Table 1 shows the experimental conditions selected to represent the whole experimental matrix for the acquisition of images by the Scanning Electron Microscope-SEM (Vega3 TESCAN). The results were compared with the ones obtained by the liberation degree analysis by using the digital optical microscopic images.

Table 1. Hammer milling conditions selected for the acquisition of images and elemental maps by using the SEM/energy dispersive spectroscopy (EDS).

\begin{tabular}{cc}
\hline Feed Mass (g) & Milling Time (s) \\
\hline 20 & 30 \\
\hline 40 & 30 \\
\hline 40 & 90 \\
\hline 80 & 90 \\
\hline
\end{tabular}

The focus of the application of the SEM-EDS was to investigate the degree of liberation of the metallic particles contained in the fine size fractions, below $0.5 \mathrm{~mm}$, generated by the hammer milling performed under different feed masses and grinding time. The PCB milled products from the size fractions $0.25-0.5 \mathrm{~mm} ; 0.125-0.25 \mathrm{~mm}$ and $<0.125 \mathrm{~mm}$ were quartered until a homogeneous material around $0.2 \mathrm{~g}$ was obtained. These particles were then mounted into epoxy resin polished sections, using ARALDITE 2020®and making sure to apply a silicone releasing agent in each polytetrafluoroethylene mold cup before pouring the particles. A special care was taken in order to avoid the physical touch of the particles, which could bring misinterpretations when dealing with such a heterogeneous material. After 36-48 hours of room temperature hardening, the specimens were polished with a sand paper (\#1200, APP, France).

\subsubsection{Digital Optical Microscope-Sample Preparation}

Representative samples from each fraction and for each of the nine conditions from the experimental matrix (feed mass vs. grinding time) were obtained through a quartering device (Minemet, France). Among the five particle size fractions, the coarser size fractions $1-2 \mathrm{~mm} ; 0.5-1 \mathrm{~mm} ; 0.25-0.5 \mathrm{~mm}$ and $0.125-0.25 \mathrm{~mm}$ were selected and imaged by the Digital Optical Microscope (Keyence-VHX-1000) that was not suitable for the finest size fraction $(<0.125 \mathrm{~mm})$. The milled PCB particles were poured into a glass petri dish and the particles were gently dispersed in order to avoid their overlapping. If necessary, for the coarser fractions, the particles were manually separated by a wooden spatula for better particle liberation/association recognition prior to the image acquisition. A series of images were taken for each sample, aiming to build a map of particle images that were analyzed to evaluate metallic particle liberation degree.

\subsection{Methods}

The chemical composition analysis of the samples has already been published in our previous reports $[12,15]$. The issues associated with the use of chemical composition is that it gives the average value of the samples disregarding the liberation degree of metals. In other words, what if a sample carries the same concentration of $\mathrm{Cu}$ as the other sample with the different liberation degree of $\mathrm{Cu}$, we cannot detect their differences. Thus, sole use of chemical composition analysis is not applicable in the liberation degree analysis, but we need to assess individual particles about their liberation status to calculate the liberation degree of a specific metal of interest (e.g., $\mathrm{Cu}$ ). 
In this study, the liberation degree of the metals of interest $(\mathrm{Cu}, \mathrm{Al}$ and "Other Metals") was calculated by the particle-counting method, which can be expressed by the following equation:

$$
\text { Liberation Degree }=\frac{N \text { free }}{\text { Nfree }+ \text { Nlocked }}
$$

where ' $N_{\text {free' }}$, indicates the number of free particles of the metal of interest and ' $N_{\text {locked }}$ ' is the number of interlocked particles, either with other metals or with non-metallic fraction, i.e., plastics, glass and ceramics.

In order to assess the dependence of the liberation degree as a function of the geometric mean particle size, Abouzeid [16] suggested the expression below to obtain the "Liberation Parameter".

$$
Y=100 \exp (-K x)
$$

where ' $Y$ ' is the liberation degree whose natural logarithmic values were plotted in normal scale as a function of the geometric mean particle size ' $x$ ', and fitted with linear regression that determines the ' $-K$ ' as the slope.

In the analysis of the images generated by both digital microscope and scanning electron microscope, the composite particles (e.g., plastic and metal interlocked in the same particle) were considered as locked particles. In case two different metals composing the same particle, these particles were taken into account, as a non-liberated particle for both metals (e.g., non-liberated $\mathrm{Al}$ and non-liberated $\mathrm{Cu}$ ).

\subsubsection{Digital Optical Microscope Imaging and Image Analysis}

The digital optical microscope (VHX-1000, Keyence) was used for image acquisition. The VHX-1000 is a versatile digital microscope that allows sharp observations of the particles through a deeper depth of field in a magnified image than regular optical microscopes. The particles were poured and spread onto a petri dish, placed on the white background stage, and then the reflected light setting was used with a white LED as a light source. The focus of the image was made using a coupled camera adapter. The magnification varied from $20-50 x$ for the coarser fractions (i.e., $1-2 \mathrm{~mm} ; 0.5-1 \mathrm{~mm}$ ) up to $100-200 x$ for the finer ones (i.e., $0.25-0.5 \mathrm{~mm}$ and $0.125-0.25 \mathrm{~mm}$ ). For each size fraction and each experimental condition (feed mass $\mathrm{x}$ grinding time), compositional images were acquired in different areas and combined through a real time 2D image stitching function of the VHX-1000, in which the stage automatically scanned and imaged in order to cover a wide area of the sample.

A first attempt using the software ImageJ for the image analysis was proven to be inefficient, since the direct interpretation of the raw image obtained with ImageJ could not define the composite particles as being single particles with both metallic and non-metallic inclusions. Instead, the software identified the composite locked particle as two or more separated particles, which is inappropriate for the purpose of our study.

In order to solve the issue of direct analysis faced when using ImageJ, another graphic software, the Inkscape, was used to count the composite particles. A color coding system was established, assigning dots with different colors to the six different types of particles of interest that were defined prior to counting, i.e., liberated $\mathrm{Cu}$, non-liberated $\mathrm{Cu}$, liberated $\mathrm{Al}$, non-liberated $\mathrm{Al}$, liberated other metals (e.g., alloys, steel scrap, lead) and non-liberated other metals, according to the following Table 2. 
Table 2. Color coding system assigned for the six different particle types counted with the Inkscape software.

\begin{tabular}{ccc}
\hline Category & Color Coding & Color \\
\hline I - Liberated Cu & $\# 008000$ & Green \\
\hline II - Non-liberated Cu & $\# 00 F F 00$ & Lime \\
\hline III - Liberated Al & $\# 800080$ & Purple \\
\hline IV - Non-liberated Al & $\#$ FF00FF & Fuchsia \\
\hline V - Liberated Other Metals & $\# 800000$ & Maroon \\
\hline VI - Non-liberated Other Metals & \#FF0000 & Red \\
\hline
\end{tabular}

Table 3 represents the total number of particles counted according to the size fractions for each different 'feed mass (g)_grinding time (s)' condition. For each sample (milling condition and different size fraction), a range between 15-99 metallic particles were observed and counted, out of around 200-400 all the particles in total.

Table 3. Number of metallic particles counted for each image corresponding to samples of each different size fraction and different feed mass $x$ grinding time condition.

\begin{tabular}{ccccc}
\hline $\begin{array}{c}\text { Feed Mass-Milling Time } \\
\text { (g-s)/Particle Size (mm) }\end{array}$ & $\mathbf{1 - 2}$ & $\mathbf{0 . 5} \mathbf{- 1}$ & $\mathbf{0 . 2 5 - 0 . 5}$ & $\mathbf{0 . 1 2 5 - 0 . 2 5}$ \\
\hline 20 g-30 s & 36 & 51 & 27 & 35 \\
\hline 20 g-60 s & 43 & 99 & 41 & 15 \\
\hline 20 g-90 s & 21 & 49 & 84 & 44 \\
\hline 40 g-30 s & 66 & 60 & 58 & 54 \\
\hline 40 g-60 s & 37 & 48 & 50 & 15 \\
\hline 40 g-90 s & 15 & 52 & 12 & 0 \\
\hline 80 g-30 s & 20 & 48 & 79 & 21 \\
\hline 80 g-60 s & 25 & 29 & 26 & 30 \\
\hline 80 g-90s & 80 & 59 & 75 & 61 \\
\hline
\end{tabular}

An example of the methodology used to count the particles is given with more details in the following Figure 1. The image corresponds to the PCB sample prepared at $80 \mathrm{~g}$ and $90 \mathrm{~s}$ (feed mass $x$ grinding time) and the coarsest product size fraction, i.e., 1-2 mm. A guidance for how the interpretation of the individual particles was performed is given in Figure 1c.

Figure 2a summarizes the procedure for the degree of liberation analysis, combining image acquisition with the Keyence VHX-1000 and then image analysis through particle counting for further calculations of the liberation degree. 


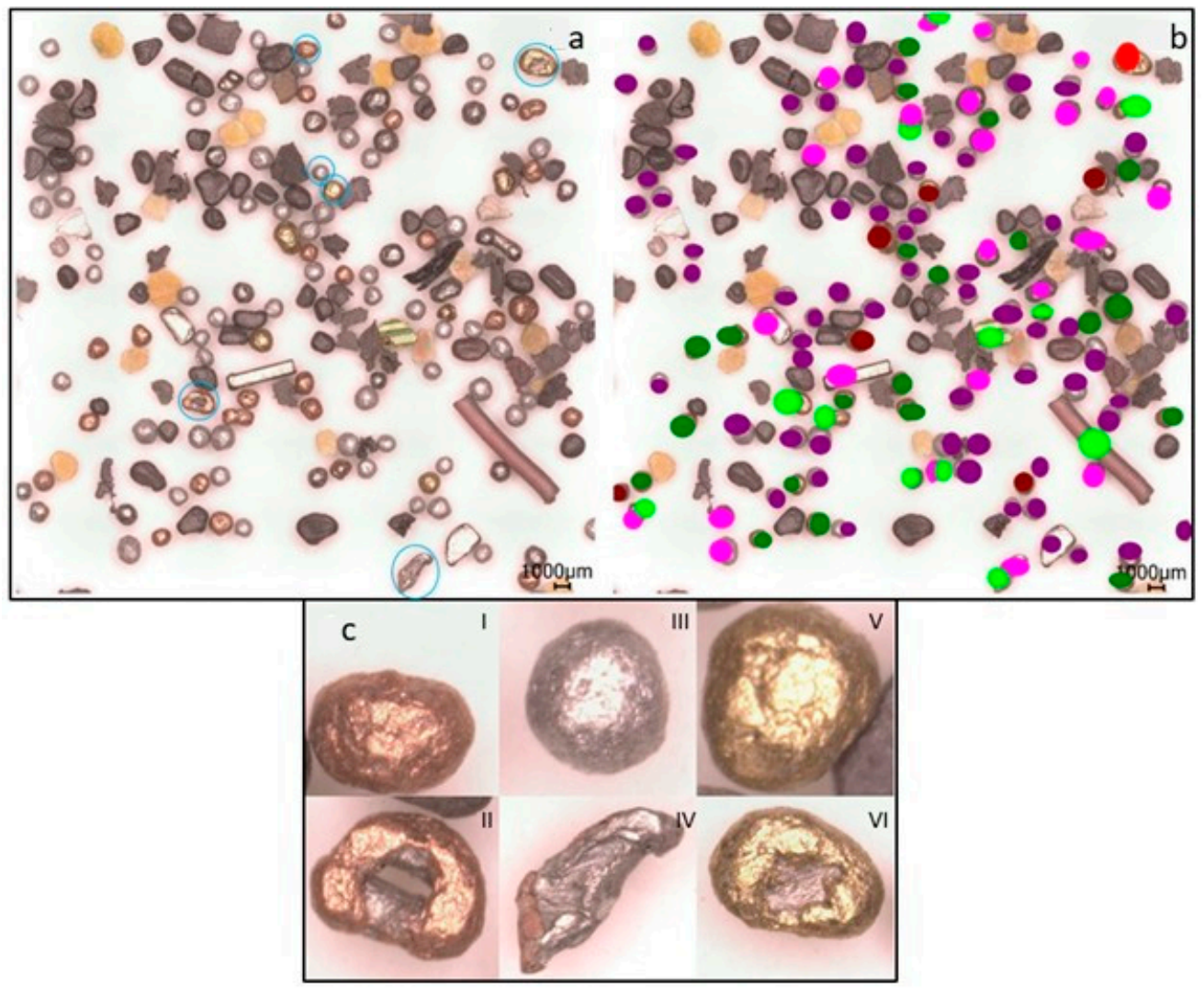

Figure 1. Images acquired from the digital microscope Keyence VHX1000 for particle counting. (a). Microscopic image obtained from the printed circuit boards (PCB) milled product condition $80 \mathrm{~g}$ and $90 \mathrm{~s}$ and size fraction 1-2 $\mathrm{mm}$ (Magnification $\mathrm{x}$ 30). (b). Inkscape treatment of the images, dots assigned for individual particles following the color coding. (c). Individual particles from each of the six different categories (I-VI) previously mentioned in Table 2.

\subsubsection{Scanning Electron Microscope (SEM) with Energy Dispersive Spectroscopy (EDS) Methodology}

Backscattered electron (BSE) images from the polished sections were obtained by a scanning electron microscope (Vega3, TESCAN), coupled with an EDS detector (Bruker) allowing the elemental mapping. The analysis was performed in the low vacuum pressurized chamber (10Pa). The $15-\mathrm{kV}$ electron beam with the intensity of 15 (arbitrary unit-defined by Vega3 TESCAN) and the working distance at around $15 \mathrm{~mm}$ were used. Incident probe current, brightness and contrast levels were set to allow the acquisition of BSE images and elemental maps with a good quality for further processing.

The BSE images provided signals from a sample polished section in greyscale that distinguishes plastics (dark) from the metallic particles (bright) due to their distinguished chemical composition contrast. Regarding the liberated and locked metallic particles (e.g., $\mathrm{Cu}, \mathrm{Fe}, \mathrm{Al}$ ), as the atomic numbers are in a closer range, the level of brightness could be similar, hence, the extra information acquired from the energy dispersive spectroscopy (EDS) was also considered. The EDS detector was used for the elemental analysis. Elemental mapping for 8 different elements: $\mathrm{C}, \mathrm{O}, \mathrm{Cu}, \mathrm{Al}, \mathrm{Fe}, \mathrm{Pb}, \mathrm{Zn}$ and $\mathrm{Au}$ (Figure 3) was acquired from the same areas as the BSE images after two 6 minutes-cycles, using the Bruker software. In addition to the BSE images in greyscale contrasting metallic and non-metallic particles (Figure 3a), the EDS detector provided elemental mapping extra information that was used to differentiate the composition of the metallic particles (Figure 3b). 

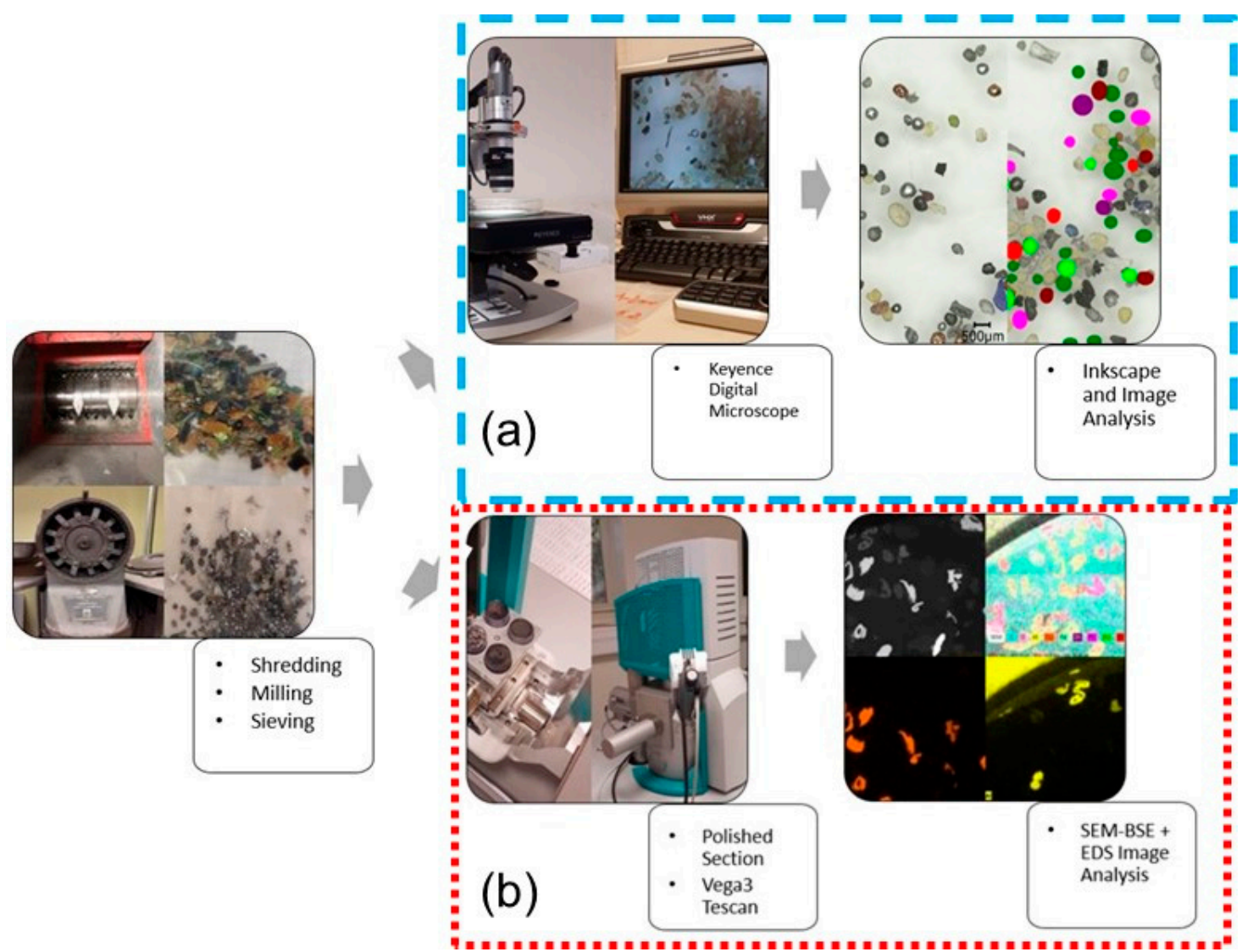

Figure 2. Flowsheet of image acquisition and analysis using (a) the Keyence Digital Microscope or (b) the Vega3 TESCAN (SEM coupled with EDS).

Table 4 represents the total number of particles counted for each polished section according to the size fractions and the different 'feed mass (g)—grinding time (s)' condition. For each of the polished sections analyzed, a range between 34-123 metallic particles were observed and counted, out of around 200-400 all the particles in total.

Analogous to the methodology used for counting with the digital microscope images, the particles were identified into six main categories: liberated and non-liberated $\mathrm{Cu}$, liberated and non-liberated $\mathrm{Al}$, and liberated/non-liberated other metals, which could include brass, steel, lead alloys.

Figure $2 \mathrm{~b}$ summarizes the procedure for the degree of liberation analysis, combining image acquisition with the Vega3 TESCAN and image analysis through particle counting methodology for further calculations of the liberation degree. 


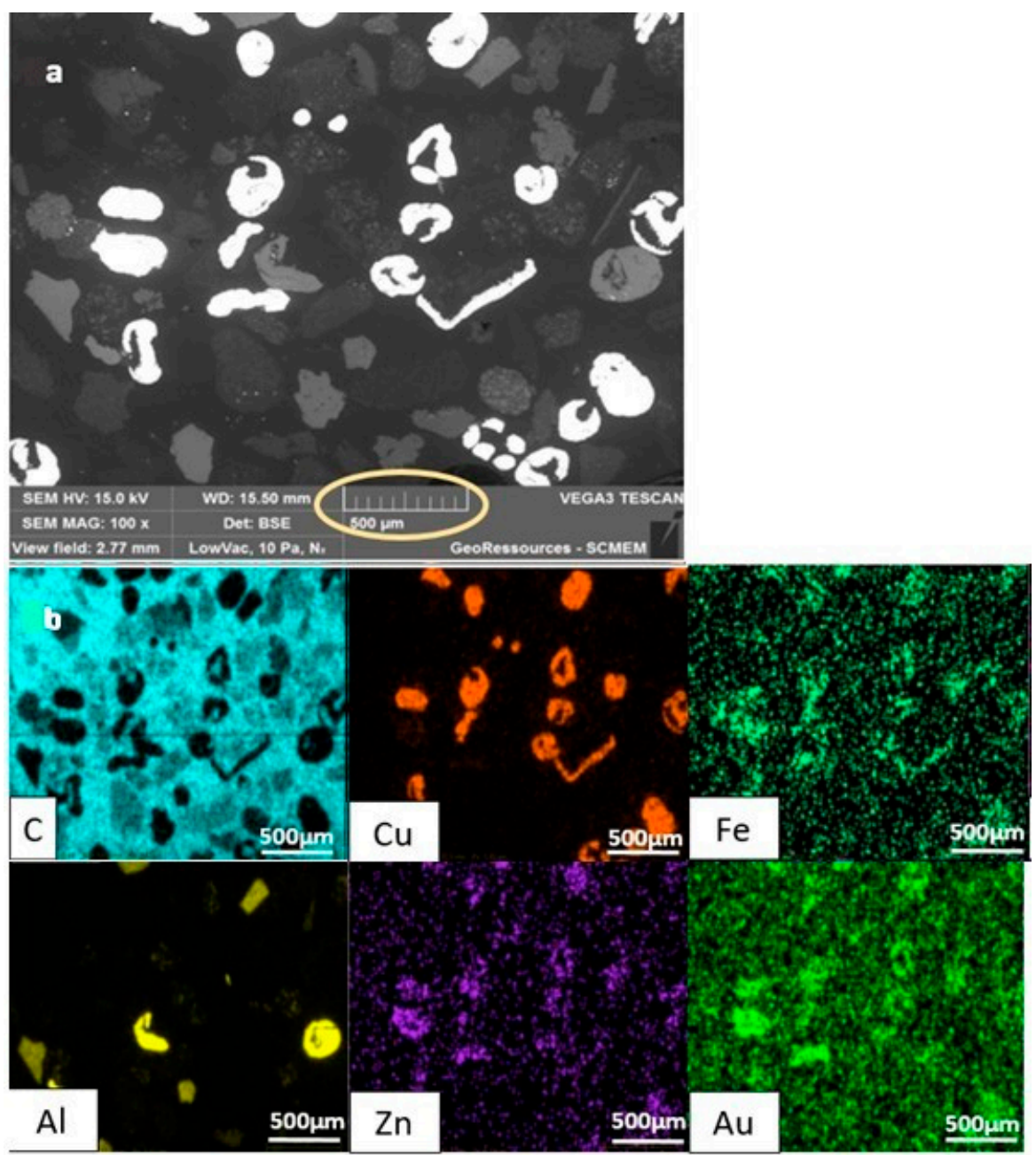

Figure 3. Backscattered electron (BSE) image and elemental maps acquired with VEGA3 TESCAN and the coupled Bruker EDS system. (a) BSE image obtained from the PCB milled product at the condition $80 \mathrm{~g}$ and $90 \mathrm{~s}$ in addition to a size fraction $0.125-0.25 \mathrm{~mm}$ (Magnification $\mathrm{x}$ 100). (b) Distribution maps for the individual element $\mathrm{C}$ (light blue), $\mathrm{Cu}$ (orange), Fe (seafoam green), Al (yellow), $\mathrm{Zn}$ (purple), or Au (green).

Table 4. Number $(\mathrm{Nb})$ of particles counted for each image corresponding to polished sections bearing particles of different size fractions for the following experimental conditions: $20 \mathrm{~g}$ and $30 \mathrm{~s} ; 40 \mathrm{~g}$ and $30 \mathrm{~s} ; 40 \mathrm{~g}$ and $90 \mathrm{~s}$, and $80 \mathrm{~g}$ and $90 \mathrm{~s}$.

\begin{tabular}{|c|c|c|c|c|c|c|}
\hline $\begin{array}{l}\text { Experimental Condition (Feed } \\
\text { Mass-Milling Time) }\end{array}$ & \multicolumn{3}{|c|}{$20 \mathrm{~g}-30 \mathrm{~s}$} & \multicolumn{3}{|c|}{$40 \mathrm{~g}-30 \mathrm{~s}$} \\
\hline Size Range, mm & $0.25-0.5$ & $0.125-0.25$ & $<0.125$ & $0.25-0.5$ & $0.125-0.25$ & $<0.125$ \\
\hline Magnification & $50 x$ & $100-200 x$ & $1000 x$ & $50 x$ & $100-200 x$ & $1000 x$ \\
\hline $\mathrm{Nb}$ images/sample & $4-5$ & $3-4$ & 2 & $4-5$ & $3-4$ & 2 \\
\hline $\mathrm{Nb}$ of particles analyzed & 51 & 39 & 78 & 65 & 123 & 34 \\
\hline $\begin{array}{l}\text { Experimental Condition } \\
\text { (feed mass-milling time) }\end{array}$ & \multicolumn{3}{|c|}{$40 \mathrm{~g}-90 \mathrm{~s}$} & \multicolumn{3}{|c|}{$80 \mathrm{~g}-90 \mathrm{~s}$} \\
\hline Size Range, mm & $0.25-0.5$ & $0.125-0.25$ & $<0.125$ & $0.25-0.5$ & $0.125-0.25$ & $<0.125$ \\
\hline Magnification & $50 x$ & 100-200x & $1000 x$ & $50 x$ & $100-200 x$ & $1000 x$ \\
\hline $\mathrm{Nb}$ images/sample & $4-5$ & $3-4$ & 2 & $4-5$ & $3-4$ & 2 \\
\hline $\mathrm{Nb}$ of particles analyzed & 66 & 53 & 68 & 41 & 84 & 43 \\
\hline
\end{tabular}




\section{Results and Discussion}

\subsection{Determination of Liberation Degree and Parameters}

Figure 4 shows the liberation degree determined by BSE images and elemental maps for $\mathrm{Cu}, \mathrm{Al}$ and other metals, as a function of milling parameters (feed mass, milling time) and product particle size. In general, with the particle size range (below $0.5 \mathrm{~mm}$ ) studied by this method, there is a clear trend of the increase in degree of liberation with a decrease in particle size. For example, with $80 \mathrm{~g}$ feed mass and $90 \mathrm{~s}$ milling time (Figure $4 \mathrm{~d}$ ), the $\mathrm{Cu}$ liberation degree was $50 \%$ in $0.25-0.5 \mathrm{~mm}$ fraction, $72 \%$ in $0.125-0.25 \mathrm{~mm}$ fraction, and $88 \%$ in $<0.125 \mathrm{~mm}$ fraction.

With less feed mass (i.e., $20 \mathrm{~g}$ feed mass and $30 \mathrm{~s}$ milling time, Figure 4a), there is a clear liberation degree contrast $(40 \%$ for $\mathrm{Cu}, 22 \%$ for $\mathrm{Al}, 8 \%$ for other metals) with the coarse size fraction $(0.25-0.5 \mathrm{~mm})$ while the contrast diminished $(68 \%$ for $\mathrm{Cu}, 60 \%$ for $\mathrm{Al}, 72 \%$ for other metals) in the finest size fraction $(<0.125 \mathrm{~mm})$ although the values are high. With increasing the feed mass (e.g., $40 \mathrm{~g}$ feed mass and $30 \mathrm{~s}$ milling time, Figure $4 \mathrm{~b}$ ), the liberation contrast is also hindered. This can be explained by the decrease in the collision probability between particles and hammers, reducing the selective liberation of different metallic components.

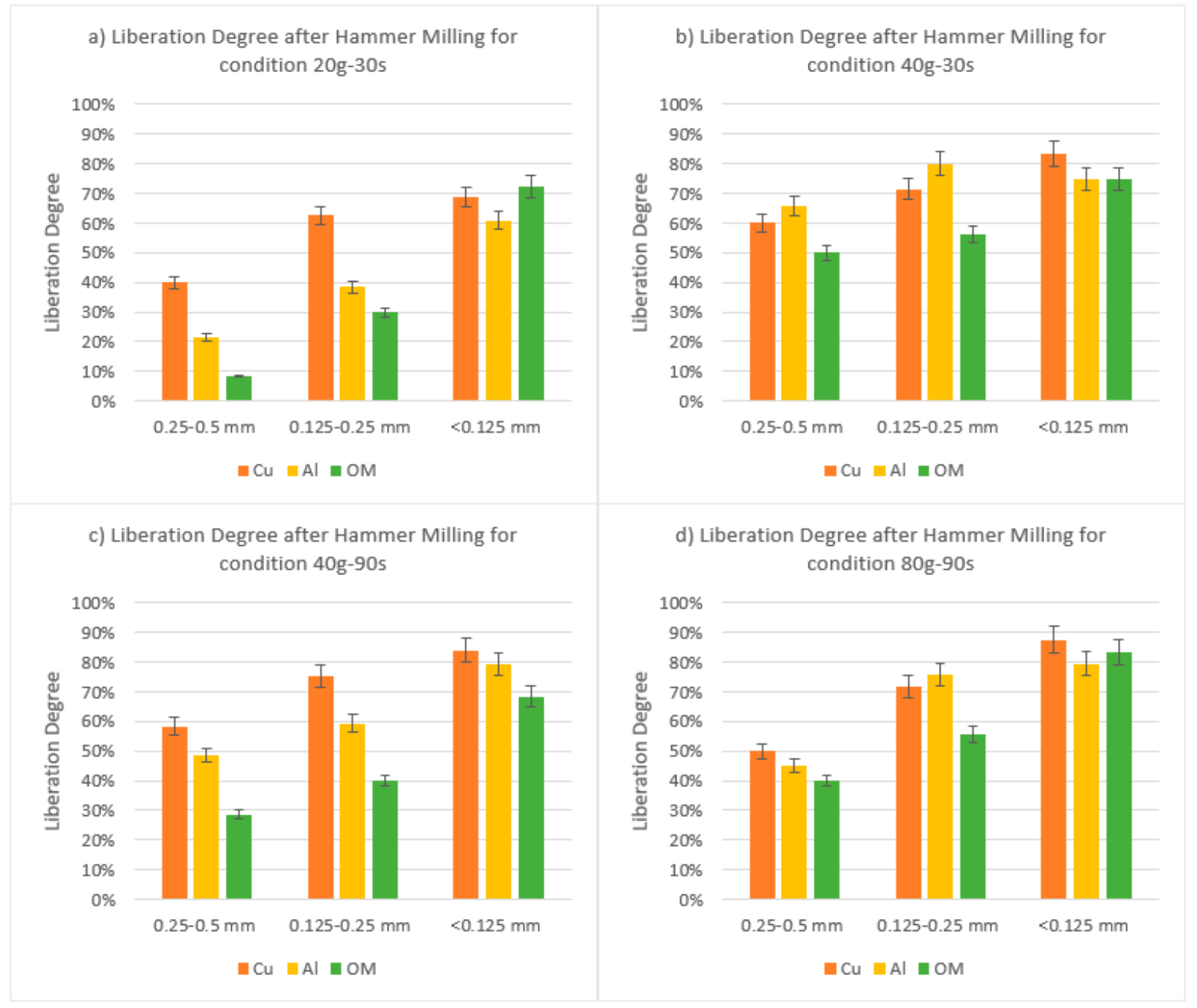

Figure 4. Degree of liberation determined by the SEM-EDS image analysis. (a) Feed $=20 \mathrm{~g}$, Milling Time $=30 \mathrm{~s} ;(\mathbf{b})$ Feed $=40 \mathrm{~g}$, Milling Time $=30 \mathrm{~s}$; (c) Feed = $40 \mathrm{~g}$, Milling Time $=90 \mathrm{~s} ;(\mathbf{d})$ Feed $=80 \mathrm{~g}$, Milling Time $=90 \mathrm{~s}$. 
Figure 5 was designed to obtain the Liberation parameter ' $K$ ' aforementioned in the methodology Section 2.2. The natural logarithm of liberation degree for $\mathrm{Cu}, \mathrm{Al}$ and the other metals were plotted against the geometric mean particle size $(\mu \mathrm{m})$ for the different feed mass and milling time conditions. The slope for the plots obtained represents $-K$ in Equation (2). In general, the larger the $K$, the larger the change in degree of liberation. In other words, the size reduction helps increasing the degree of liberation while the smaller the $K$, the little effect of size reduction on increasing the degree of liberation. The objective of $K$ values determination by linear regression is to test capturing and explaining the liberation degree trend with them.

Figure 5 a shows the effect of size reduction on the better liberation with a decrease in particle size. It also indicates the liberation is more enhanced with other metals $(K=0.0082)$, followed by $\mathrm{Al}$ $(K=0.0039)$ and then $\mathrm{Cu}(K=0.0022)$. With increasing the feed mass to $40 \mathrm{~g}$ and $80 \mathrm{~g}$, the liberation contrast among different metals decreased. It is proven by the closer $K$ values among three categories than the $K$ value difference with $20 \mathrm{~g}$. With $40 \mathrm{~g}$ feed mass and $90 \mathrm{~s}$ milling time, $K$ values were 0.0032 for other metals, 0.0018 for $\mathrm{Al}$ and 0.0014 for $\mathrm{Cu}$ while with $80 \mathrm{~g}$ feed mass and $90 \mathrm{~s}$ milling time, $K$ values were 0.0027 for other metals, 0.0023 for $\mathrm{Al}$ and $0.0021 \mathrm{for} \mathrm{Cu}$. This trend indicates that with increase in feed mass, the selective liberation is hindered. It can be explained by the less probability of collision between particles and hammers with the higher feed mass, and thus diminishment of liberation contrast among different metals.

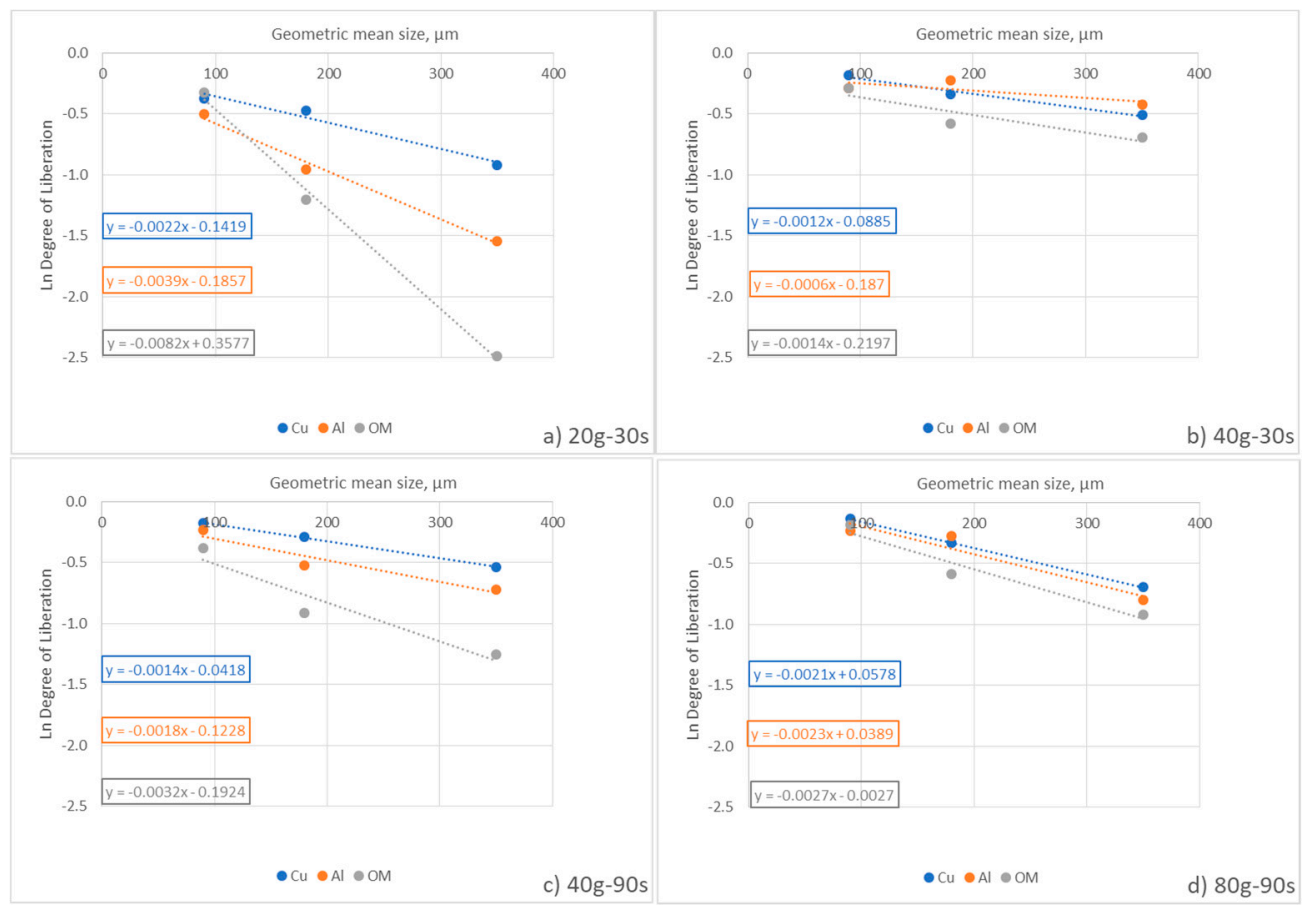

Figure 5. Ln (degree of liberation determined by SEM-EDS image and elemental mapping analysis) plot as a function of geometrical mean. (a) Cu, $\mathrm{Al}$ and $\mathrm{OM}-20 \mathrm{~g}$ feed and $30 \mathrm{~s}$ milling time, (b) $\mathrm{Cu}, \mathrm{Al}$ and $\mathrm{OM}-40 \mathrm{~g}$ feed and $30 \mathrm{~s}$ milling time, (c) $\mathrm{Cu}, \mathrm{Al}$ and $\mathrm{OM}-40 \mathrm{~g}$ feed and $90 \mathrm{~s}$ milling time, and (d) $\mathrm{Cu}$, $\mathrm{Al}$ and $\mathrm{OM}-80 \mathrm{~g}$ feed and $90 \mathrm{~s}$ milling time.

Figure 6 shows the liberation degree determined by the digital microscope image analyses, following the methodology described in the Section 2.2.1. There is a clear trend of higher liberation towards the finest fractions analyzed (i.e., $0.125-0.25 \mathrm{~mm}$ ), and this is true for all the three metals of interest, $\mathrm{Cu}, \mathrm{Al}$ and the group of other metals. This trend agreed with a previous report [11] with some difference in the absolute value. In the current study, the degree of liberation of at least $50 \%$ for these three metals was achieved in the finest fractions analyzed. The influence of milling time variation (i.e., 30, 60 and $90 \mathrm{~s}$ ) is clearly visible in terms of increasing the liberation degree. For example, the 
liberation degree of $\mathrm{Cu}$ in the size fraction of $1-2 \mathrm{~mm}$ for $30 \mathrm{~s}, 60 \mathrm{~s}$ and $90 \mathrm{~s}$ were $8 \%, 27 \%$ and $65 \%$, respectively (Figure 6a). With decreasing particle size, the liberation degree increased as agree with the results obtained by SEM-EDS image analysis (Figures 4 and 5). For example, the liberation degree of $\mathrm{Cu}$ in the size fraction of $30 \mathrm{~s}$ for $1-2 \mathrm{~mm}, 0.5-1 \mathrm{~mm}, 0.25-0.5 \mathrm{~mm}$, and $0.125-0.25 \mathrm{~mm}$ was $8 \%, 56 \%$, $65 \%$ and $63 \%$, respectively (Figure 6a). The above two trends were obtained with two other metal categories and other feed mass, in general, with some exceptions (e.g., $\mathrm{Cu}$ liberation degree decrease with size reduction with $80 \mathrm{~g}$ feed due to selective agglomeration, Figure $6 \mathrm{c}$ ).
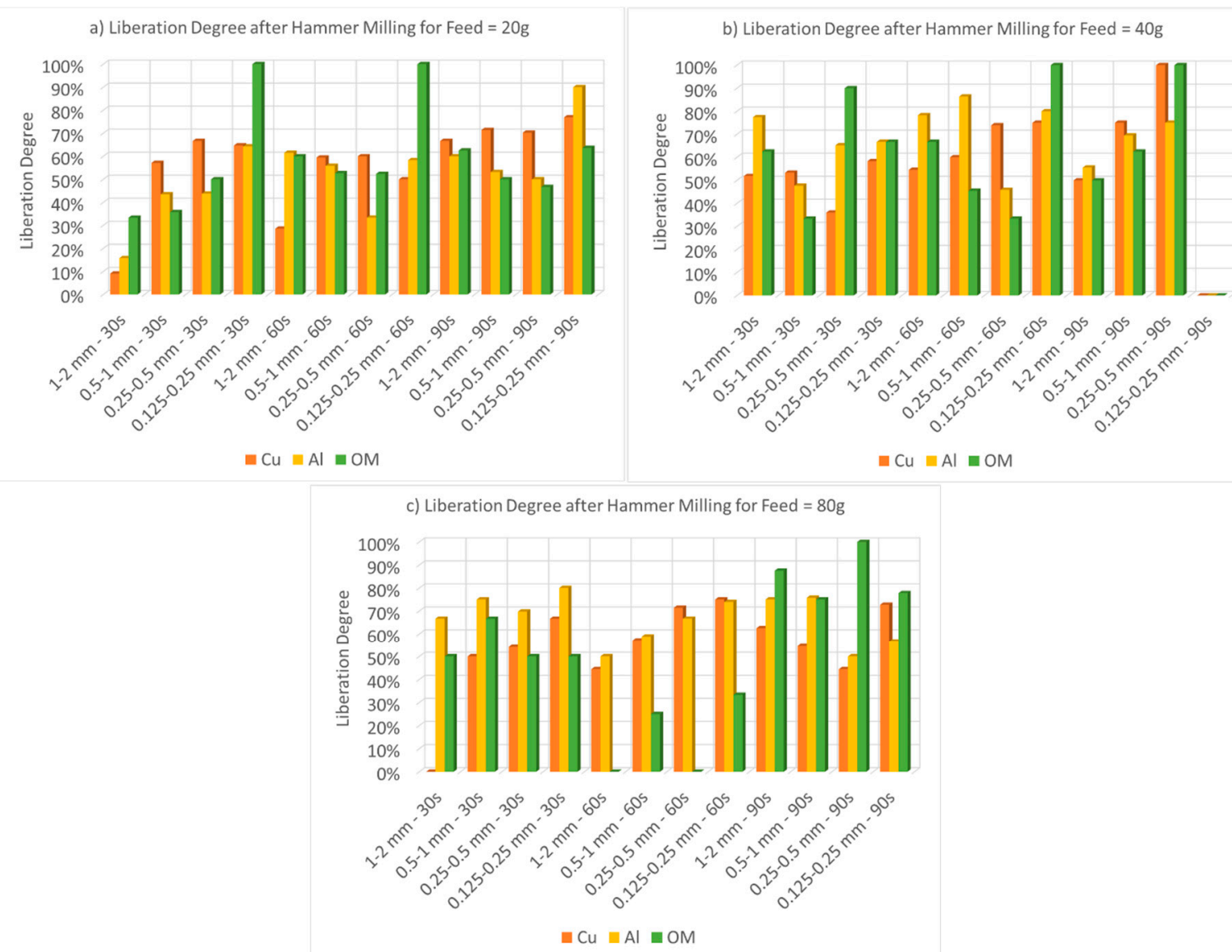

Figure 6. Degree of Liberation determined by the digital microscope image analysis. (a) Feed $=20 \mathrm{~g}$; (b) Feed $=40 \mathrm{~g}$ and $(\mathrm{c})$ Feed $=80 \mathrm{~g}$. For Feed $=40 \mathrm{~g}$, no metallic particles were identified in the size fraction $0.125-0.25 \mathrm{~mm}$. Error values are up to $5 \%$.

Despite being more liberated in the finest fractions in general, our previous studies $[12,15]$ also showed the metals, especially $\mathrm{Cu}$, were often enriched in coarser fractions (e.g., 1-2 mm) explained by selective agglomeration. Hence, the relationship among particle agglomeration, particle liberation and metallic enrichment is aimed to further understand in this study, and should be useful for further beneficiation stages. In our previous selective milling study [15], the optimal operational conditions for selective size reduction and highest recovery of $\mathrm{Cu}$ in the finest fractions $(0.125-0.250 \mathrm{~mm}$ and $<0.125 \mathrm{~mm}$ ) was feed mass (20 g) and milling time (90 s), with $89 \%$ copper recovery. Figure 6 shows that such conditions indicate a liberation degree for $\mathrm{Cu}$ around $80 \%$, which is not the highest value, but high enough for the product with the high recovery of Cu previously reported [15], for the subsequent beneficiation stages. The conditions for selective agglomeration (taking place in the coarse fractions) were reported as $80 \mathrm{~g}$ feed mass and $90 \mathrm{~s}$ milling time in our previous work [15], with a recovery of copper at $40 \%(0.5-1 \mathrm{~mm})$. Figure $6 \mathrm{c}$ shows that the liberation degree of $\mathrm{Cu}$ in the product size fraction $0.5-1 \mathrm{~mm}$ generated under these conditions was around $53 \%$. It indicates the presence of other 
components than $\mathrm{Cu}$ in those agglomerates formed during hammer milling operation although the highest recovery $(40 \%)$ and enrichment (1.3) of $\mathrm{Cu}$ in that size fraction among all the milling conditions tested [15]. A further study of selective agglomeration and selective liberation will be of great interest in terms of practical use of agglomeration as a selective material recovery process.

Figure 7, analogous to Figure 5 for SEM-EDS image analysis, was designed to obtain the liberation parameter ' $K$ ' aforementioned in the methodology Section 2.2. The natural logarithm of the liberation degree for $\mathrm{Cu}, \mathrm{Al}$ and the other metals were plotted against the geometric mean particle size $(\mu \mathrm{m})$ for the different feed mass and milling time conditions. For the digital microscope, the products from all the nine conditions were analyzed. For example, Figure $7 \mathrm{~g}$ shows that the liberation parameter of other metals is higher with less milling time ( $K=0.0009$ for $30 \mathrm{~s})$ for $20 \mathrm{~g}$ feed than the one with longer milling time ( $K=0.0002$ for $90 \mathrm{~s})$, indicating the liberation contrast in different size fraction was better with less milling time.
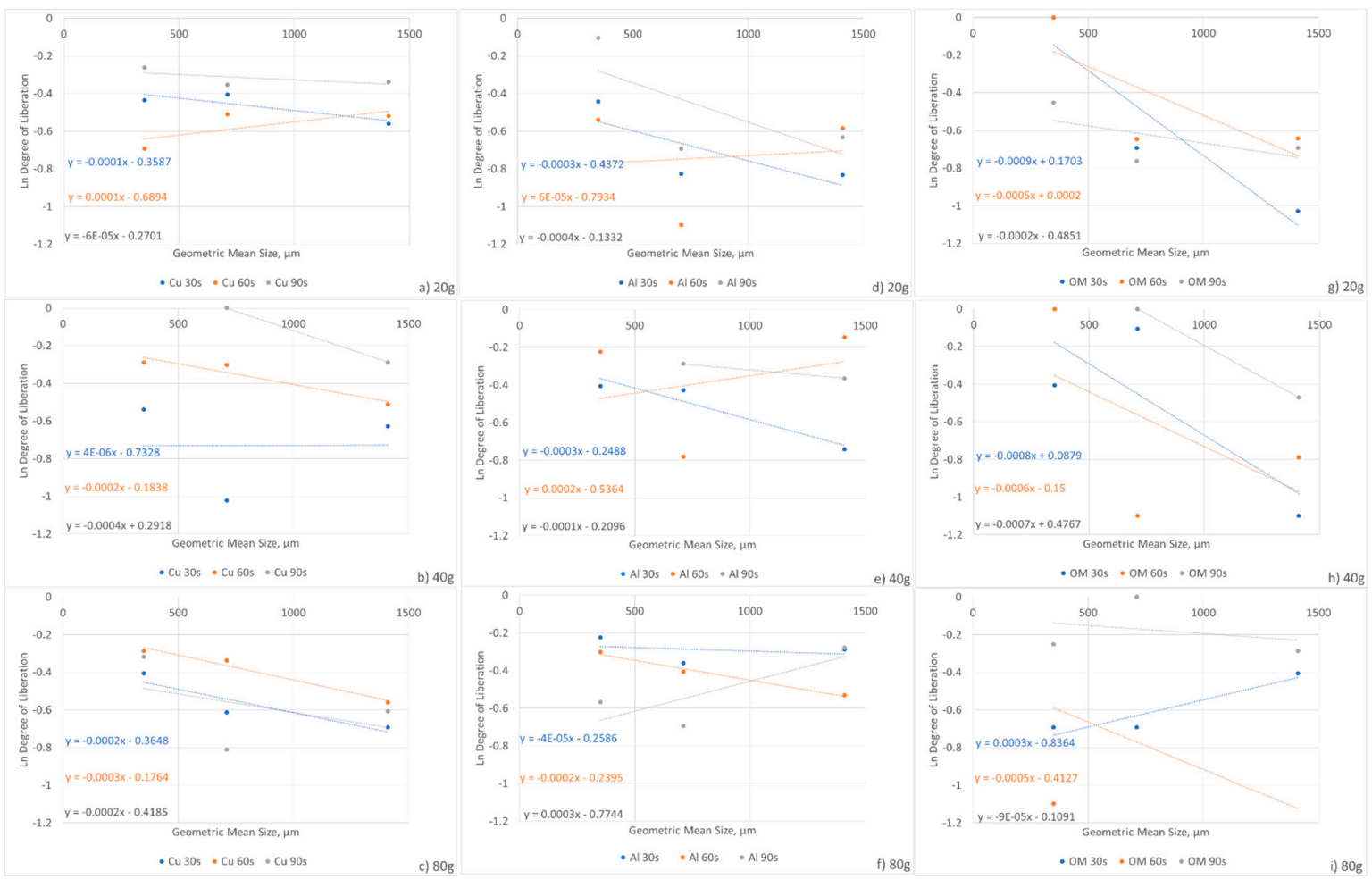

Figure 7. Ln (degree of liberation determined by the digital microscope image analysis) plot as a function of geometrical mean. (a) Cu-20 g feed, (b) Cu-40 g feed, (c) Cu-80 g feed, (d) Al-20 g feed, (e) Al-40 $\mathrm{g}$ feed, (f) Al-80 $\mathrm{g}$ feed, (g) other metals-20 $\mathrm{g}$ feed, (h) other metals-40 $\mathrm{g}$ feed, and (i) other metals- $80 \mathrm{~g}$ feed.

Due to the particle agglomeration discussed and previously reported [12,15], the plot given in Figure 7 that contains the results from coarse size fractions $(0.125-2 \mathrm{~mm})$ is more complex than the ones given in Figure 5 that is based on the results from fine size fractions $(<0.5 \mathrm{~mm})$ where the agglomerates do not exist. Thus, the general trend will be further discussed with the summary of liberation parameters given in Table 5 .

Table 5 summarizes the liberation parameter ' $K$ ' for the three different metal categories and the different milling conditions analyzed with both digital optical microscope and the SEM-EDS images. In general, the liberation parameter $K$ is higher with less feed mass and less milling time. For example, $K$ determined by digital microscopic image analysis for other metals at $30 \mathrm{~s}$ milling time were $0.9 \times 10^{-3}$ $(20 \mathrm{~g}), 0.8 \times 10^{-3}(40 \mathrm{~g})$, and $0.3 \times 10^{-3}(80 \mathrm{~g})$ while $\mathrm{K}$ at $20 \mathrm{~g}$ feed mass were $0.9 \times 10^{-3}(30 \mathrm{~s}), 0.5 \times 10^{-3}$ 
$(60 \mathrm{~s})$, and $0.2 \times 10^{-3}(90 \mathrm{~s})$. It indicates that with less feed mass and milling time enhanced selective liberation of those metallic components.

Also, in general, the order of $K$ was other metals $\left(0.9 \times 10^{-3}(20 \mathrm{~g}\right.$ and $\left.30 \mathrm{~s})\right)>\mathrm{Al}\left(0.3 \times 10^{-3}(20 \mathrm{~g}\right.$ and $30 \mathrm{~s}))>\mathrm{Cu}\left(0.1 \times 10^{-3}(20 \mathrm{~g}-30 \mathrm{~s})\right)$ that reflected the order of facile selective liberation. On the other hand, such a contrast was hindered with higher feed mass and longer milling time $\left(K=0.09 \times 10^{-3}\right.$ (80 g-90 s) for other metals, $K=0.3 \times 10^{-3}(80 \mathrm{~g}-90 \mathrm{~s})$ for $\mathrm{Al}, K=0.02 \times 10^{-3}(80 \mathrm{~g}-90 \mathrm{~s})$ for $\mathrm{Cu}$ ). The values cited above were $K$ determined by digital microscopic image analysis. The objective of $K$ values determination by linear regression is to test capturing and explaining the liberation degree trend with them, not the absolute values obtained by two different methods. As a result, shown above, we basically found the trend in $K$ values obtained by the both digital microscopic image analysis and SEM-EDS image analysis are the same. As a conclusion, we succeeded to achieve this objective and we confirmed our proposition was valid as shown in the results and discussion. In this sense, the both methods we proposed in this article are reliable while they have some preference in terms of the type of sample. In particular, coarser particle size is preferred with the digital microscope analysis, while fine particle size can utilize the higher magnification capability of SEM-EDS than the other one. In other words, depending on the particle size range, a more suitable method can be selected. On the other hand, if one wishes to evaluate the liberation degree trend of a wide range of particle size, the combination of two methods can give the better idea than the application of either method due to their size preference mentioned above

Table 5. Liberation parameters of major metals obtained for the products generated at different milling conditions, determined by digital microscope and SEM-EDS image analysis. 'n.d. = not determined'.

\begin{tabular}{cccccccc}
\hline & & \multicolumn{6}{c}{ Liberation Parameter, $k\left(x \mathbf{1 0}^{-3}\right)$} \\
\cline { 3 - 7 } Feed Mass (g) & Milling Time (s) & \multicolumn{2}{c}{ Digital Microscope } & \multicolumn{3}{c}{ SEM-EDS } \\
\cline { 3 - 8 } & & $\mathbf{C u}$ & Al & OM & Cu & Al & OM \\
\hline 20 & 30 & 0.1 & 0.3 & 0.9 & 2.2 & 3.9 & 8.2 \\
\hline 20 & 60 & 0.1 & 0.06 & 0.5 & n.d. & n.d. & n.d. \\
\hline 20 & 90 & 0.06 & 0.4 & 0.2 & n.d. & n.d. & n.d. \\
\hline 40 & 30 & 0.004 & 0.3 & 0.8 & 0.6 & 1.2 & 1.4 \\
\hline 40 & 60 & 0.2 & 0.2 & 0.6 & n.d. & n.d. & n.d. \\
\hline 40 & 90 & 0.4 & 0.1 & 0.7 & 1.4 & 1.8 & 3.2 \\
\hline 80 & 30 & 0.2 & 0.04 & 0.3 & n.d. & n.d. & n.d. \\
\hline 80 & 60 & 0.3 & 0.2 & 0.5 & n.d. & n.d. & n.d. \\
\hline 80 & 90 & 0.02 & 0.3 & 0.09 & 2.1 & 2.3 & 2.7 \\
\hline
\end{tabular}

\subsection{Comparison between the Digital Optical Microscope and SEM-EDS Image Analyses}

Although not all the products generated by all the milling conditions were observed by using the SEM-EDS, our analysis procedures are hereby compared and summarized in Table 6.

The possibility of analyzing the samples with their natural colors is a valuable advantage for waste PCB studies, while it can be hindered by the artificial colors of BSE images coupled with EDS in the scanning electron microscopy. The major drawbacks when using the digital microscope for the analysis were the time needed for imaging and the particle recognition, depending on the photo quality. Since the digital microscope is not possible to perform an elemental mapping, it is recommended that the particles are coarse enough for the optimal visualization. 
Table 6. Advantages and drawbacks of liberation degree analysis of mechanically processed printed circuit boards (PCB) particles by using digital microscope and SEM-EDS.

\begin{tabular}{|c|c|c|c|}
\hline \multicolumn{2}{|c|}{ Digital Microscope } & \multicolumn{2}{|c|}{ SEM-EDS } \\
\hline Advantages & Drawbacks & Advantages & Drawbacks \\
\hline $\begin{array}{l}\text { Feasible to directly } \\
\text { manipulate particles on a } \\
\text { petri dish prior to image } \\
\text { acquisition, in order to } \\
\text { confirm whether particles } \\
\text { are simply overlapped or } \\
\text { actually locked. }\end{array}$ & $\begin{array}{l}\text { Results are dependent on } \\
\text { the skills of the operator } \\
\text { and prior knowledge } \\
\text { about the sample to be } \\
\text { analyzed. }\end{array}$ & $\begin{array}{l}\text { Combination of BSE } \\
\text { images and elemental } \\
\text { maps can solve more } \\
\text { complex associations. }\end{array}$ & $\begin{array}{l}\text { SEM is more expensive, large } \\
\text { and must be housed in an area } \\
\text { free of any possible electric, } \\
\text { magnetic or vibration } \\
\text { interference. }\end{array}$ \\
\hline $\begin{array}{l}\text { Easy to use. Images with } \\
\text { natural colors. }\end{array}$ & $\begin{array}{l}\text { Time consuming for } \\
\text { image acquisition and } \\
\text { analysis. }\end{array}$ & $\begin{array}{l}\text { Feasible to reveal } \\
\text { information regarding } \\
\text { texture and chemical } \\
\text { composition. }\end{array}$ & $\begin{array}{l}\text { Special care must be taken with } \\
\text { sample preparation and } \\
\text { equipment parameters such as } \\
\text { the beam control. }\end{array}$ \\
\hline
\end{tabular}

It is known from the literature [11] and our previous study [15] that a hammer mill, due to the impact force grinding mechanism, could bundle up and/or encase the liberated metal particles, particularly aluminum, into ball-shaped particles. Such phenomena could mislead the determination of the liberation degree, since plastics/other metals might be aggregated within such ball-shaped particles, hence, it could overestimate the liberation degree of the metallic particles, especially with the digital microscope image analysis. In addition, in general, the stereological bias in 2D sectional analysis [6] might affect the results obtained via both digital microscope and SEM-EDS image analyses.

The SEM is an expensive and more complex equipment to achieve a higher magnification than the digital microscopes. For the applicability to the mechanically processed PCB particles, it can be used for imaging and counting to assess the liberation degree and often for the visualization of particle surface morphology and investigation of particle shapes in a detailed context, due to various detector options applicable to wide range of applications. One more interesting advantage is the semi-quantitative elemental mapping that was used with BSE images and discussed in this paper.

The instrumentation is not exactly hard to manage but the sample preparation procedure requires special care before being placed in the SEM vacuum chamber. An inappropriate sample can result in signal artifacts that could hinder the useful information especially for the X-ray analysis (e.g., from non-flat sample surface).

\section{Conclusions}

The liberation degree of metal particles in mechanically processed PCBs was analyzed using digital microscopic images in comparison with the analysis of BSE images and elemental maps obtained by SEM-EDS. Results between the two methods showed some similarities and discrepancies. Digital microscopic images can utilize the variety of colors to distinguish different particles while the combination of BSE images with the elemental mapping allows the elemental distribution within the particles in order to calculate the degree of liberation of metallic particles. Results showed that in general liberation degree was higher in finer particle size (selective size reduction) agreed with previous studies, apart from the coarsest fraction (agglomeration). The liberation parameter $K$ also increased with less feed mass and milling time in hammer milling operation, indicating the enhancement of selective liberation under those conditions.

In order to predict selective liberation of the metal components from the non-metallic portion into different size fractions, a model of the liberation parameter ' $K$ ' based on a 2-level factorial design was attempted. This modelling was not satisfactory, probably due to a lack of a precise data set in a wide range of particle sizes. Especially in coarse size fractions, the higher number of particle counting is recommended. Thus, results are not shown in this paper. Such investigation will be further addressed in a future research. 
Author Contributions: Conceptualization, A.O.; methodology, P.P.G. and A.O.; software, P.P.G. and A.O.; validation, P.P.G. and A.O.; formal analysis, P.P.G. and A.O.; investigation, P.P.G. and A.O.; resources, A.O.; data curation, P.P.G. and A.O.; writing-original draft preparation, P.P.G. and A.O.; writing-review and editing, A.O.; visualization, P.P.G. and A.O.; supervision, A.O.; project administration, A.O.; funding acquisition, A.O.

Funding: The authors wish to acknowledge the financial support from the EMerald program.

Acknowledgments: The authors wish to acknowledge the technical support from GeoRessources.

Conflicts of Interest: The authors declare no conflict of interest.

\section{References}

1. Eurostat. Available online: http://ec.europa.eu/eurostat/web/waste/key-waste-streams/weee (accessed on 18 May 2018).

2. Burat, F.; Özer, M. Physical separation route for printed circuit boards. Phys. Probl. Min. Process. 2017, 54, 554-566.

3. Park, S.; Kim, S.; Han, S.; Kim, B.; Kim, B.; Han, Y.; Park, J. Liberation Characteristics Assessment for Copper Component in PCB Comminution Product by Image Analysis. Mater. Trans. 2018, 59, 1493-1500. [CrossRef]

4. Das, A.; Vidyadhar, A.; Mehrotra, S.P. A novel flowsheet for the recovery of metal values from waste printed circuit boards. Resour. Conserv. Recycl. 2009, 53, 464-469. [CrossRef]

5. Wills, B.; Finch, J.A. Wills' Mineral Processing Technology: An Introduction to the Practical Aspects of Ore Treatment and Mineral Recovery. In Butterworth-Heinemann; Elsevier: Amsterdam, The Netherlands, 2016.

6. Ueda, T.; Oki, T.; Koyanaka, S. Effect of Particle Shape on the Stereological Bias of the Degree of Liberation of Biphase Particle Systems. Mater. Trans. 2017, 58, 280-286. [CrossRef]

7. Kahn, H.; Mano, E.S.M.; Tassinari, M.M.M.L. Image Analysis Coupled with A SEM-EDS Applied to the Characterization Of A Zn-Pb Partially Weathered Ore. J. Miner. Mater. Charact. Eng. 2002, 1, 1-9.

8. Goodall, W.R.; Scales, P.J. An overview of the advantages and disadvantages of the determination of gold mineralogy by automated mineralogy. Miner. Eng. 2007, 20, 506-517. [CrossRef]

9. Otsuki, A.; Chen, Y.; Zhao, Y. Characterization and beneficiation of complex ores for sustainable use of mineral resources: Refractory gold ore beneficiation as an example. Int. J. Soc. Mater. Eng. Resour. 2014, 20, 126-135. [CrossRef]

10. Otsuki, A. Non-destructive liberation analysis of printed circuit board. In Proceedings of the 16th International Waste Management and Landfill Symposium, Sardinia, Italy, 2-6 October 2017.

11. Zhang, S.; Forssberg, E. Intelligent liberation and classification of electronic scrap. Powder Technol. 1999, 105, 295-301. [CrossRef]

12. Otsuki, A.; Gonçalves, P.P.; Stieghorst, C.; Révay, Z. Non-destructive characterization of mechanically processed waste printed circuit boards: X-ray fluorescence spectroscopy and prompt gamma activation analysis. J. Composite Sci. 2019, 3. [CrossRef]

13. Koyanaka, S.; Endoh, S.; Ohya, H. Effect of impact velocity control on selective grinding of waste printed circuit boards. Adv. Powder Technol. 2006, 17, 113-126. [CrossRef]

14. Chao, G.; Hui, W.; Wei, L.; Jiangang, F.; Xin, Y. Liberation characteristic and physical separation of printed circuit board (PCB). Waste Manag. 2011, 31, 2161-2166.

15. Otsuki, A.; Gonçalves, P.P.; Leroy, E. Selective milling and elemental assay of printed circuit board particles for their recycling purpose. Metals 2019. [CrossRef]

16. Abouzeid, S. Mineral Processing Lab Manual; Trans. Tech. Publications: Clausthal-Zellerfeld, Germany, 1990.

(C) 2019 by the authors. Licensee MDPI, Basel, Switzerland. This article is an open access article distributed under the terms and conditions of the Creative Commons Attribution (CC BY) license (http://creativecommons.org/licenses/by/4.0/). 